\title{
Collateral methotrexate resistance in cisplatin-selected murine leukemia cells
}

A. Bhushan ${ }^{1}$,

M.P. Hacker ${ }^{2}$ and

T.R. Tritton ${ }^{3}$

\author{
1Department of Pharmaceutical Sciences, College of Pharmacy, Idaho State U niversity, \\ Pocatello, ID, USA \\ ${ }^{2}$ Department of Health Sciences, Grand Valley State University, Allendale, MI, USA \\ ${ }^{3}$ Haverford College, Haverford, PA, USA
}

\section{Correspondence \\ A. Bhushan \\ Department of Pharmaceutical \\ Sciences \\ College of Pharmacy \\ Idaho State University \\ Pocatello, ID 83209-8334 \\ USA}

Presented at the I International Symposium on "Signal Transduction and Gene Expression in Cell Proliferation and Differentiation", São Paulo, SP, Brasil,

August 31-September 2, 1998.

Research supported by the American Cancer Society (No. DHP-170).

Received November 4, 1998 Accepted November 19, 1998

\section{Abstract}

Resistance to anticancer drugs is a major cause of failure of many therapeutic protocols. A variety of mechanisms have been proposed to explain this phenomenon. The exact mechanism depends upon the drug of interest as well as the tumor type treated. While studying a cell line selected for its resistance to cisplatin we noted that the cells expressed $a>25,000$-fold collateral resistance to methotrexate. Given the magnitude of this resistance we elected to investigate this intriguing collateral resistance. From a series of investigations we have identified an alteration in a membrane protein of the resistant cell as compared to the sensitive cells that could be the primary mechanism of resistance. Our studies reviewed here indicate decreased tyrosine phosphorylation of a protein (molecular mass $=66$ ) in the resistant cells, which results in little or no transfer of methotrexate from the medium into the cell. Since this is a relatively novel function for tyrosine phosphorylation, this information may provide insight into possible pharmacological approaches to modify therapeutic regimens by analyzing the status of this protein in tumor samples for a better survival of the cancer patients.

\section{Introduction}

Cisplatin [cis-diammine dichloroplatinum (II)] (DDP) is among the most active chemotherapeutic agents available for treatment of patients with ovarian, testicular, bladder, head and neck, and lung cancers (1-3). Despite the extensive use of DDP, its clinical value has been limited, in part due to the development of resistant cancer cells. Therefore, a great deal of research has been directed towards overcoming resistance by understanding the interactions between cisplatin and DNA.

Acquisition of resistance to the primary drug, DDP, and cross resistance to unrelated drugs has plagued the treatment of ovarian cancer and most solid tumors (4-7). Studies by several investigators have implicated an

\section{Key words}

- Methotrexate transport

- Resistance

- Cisplatin

- Leukemia

- Phosphorylation interaction between DDP and folate metabolism in the acquisition of clinical resistance $(8,9)$. DDP resistance is sometimes associated with cross resistance to the folate antagonist methotrexate (MTX) as seen in P388 murine leukemia (8), SSC-25 human squamous cell carcinoma (9) and A2780 human ovarian cancer cell lines (10). The link between DDP resistance and the expression of collateral resistance to MTX is not understood.

DDP enters the cell by diffusion. Hydrolysis of its chloride ions generates an active aquated platinum species (11). These active complexes react with DNA forming inter-strand and intra-strand crosslinks which alter the tertiary structure of DNA and inhibit DNA functions $(12,13)$. Resistance to DDP 
has been explained by a number of mechanisms: enhanced repair of DDP-DNA lesions, altered DDP uptake, and altered intracellular sequestration of DDP by such endogenous compounds as glutathione and metallothionein.

\section{Methotrexate action and resistance}

The cytotoxicity of methotrexate occurs through competitive inhibition of dihydrofolate reductase (DHFR) (14). MTX binds very tightly, in a nearly stoichiometric relationship to DHFR and prevents DHFR from maintaining a cellular pool of the reduced folate, tetrahydrofolate. Tetrahydrofolates serve as cofactors in the de novo synthesis of purine nucleotides and thymidylate (15). The most frequent explanation of MTX-induced cell death is through unbalanced growth resulting from a depletion of thymidine pools. Resistance to MTX has been reported to be mediated through increased DHFR gene copy number, altered DHFR binding to MTX, impaired polyglutamation of MTX and decreased MTX uptake. The latter mechanism will be the focus of this review.

\section{Methotrexate transport and tyrosine phosphorylation}

Unlike DDP, MTX utilizes a specific active folate transport system to gain access to the cellular interior. L1210 mouse leukemia cells contain a complex high-affinity transport system for accumulation of MTX and reduced folate compounds. MTX transport in L1210 cells is mediated by a $48-\mathrm{kDa}$ integral membrane protein and a $38-\mathrm{kDa}$ cytosolic or peripheral protein which are also involved in intracellular transport of reduced folates (16). Using a photoaffinity probe, Freisheim and his co-workers (17) observed that MTX was first associated with this larger molecular weight protein $(66 \mathrm{kDa})$ and was subsequently transported to the 48$\mathrm{kDa}$ protein. Given the close similarity in weight to albumin this $66-68-\mathrm{kDa}$ protein was assumed to be albumin. We demonstrate that this protein is not albumin and is intimately involved in MTX transport.

Others have observed that resistance to MTX is often manifested by a decrease in the transport of drug from the extracellular space to the interior of the cell (18-21). It has been demonstrated that folate-binding proteins in human leukemia CEM cells selected for MTX resistance have relatively poor affinity for MTX $(22,23)$.

\section{Mechanism of methotrexate resistance in cisplatin-selected cells}

Below we provide a stepwise analysis of the two cell lines which led to our first reports depicting the association of tyrosine phosphorylation with methotrexate transport in cisplatin-selected cells $(24,25)$. The results reviewed here demonstrate that L1210 cells made 40-60-fold resistant to DDP express very pronounced collateral resistance to MTX and that the resistance to MTX appears to be directly related to changes in membrane-associated folate transport proteins. In these resistant cells, MTX association to the membrane is only 2 -fold less, but no transport to the inside of these cells is detected.

While defining the profile of resistance to antimetabolites in L1210/DDP cells we found that the L1210/DDP cells were $>25,000$-fold resistant to MTX (24). Many cell lines have been described that are resistant to MTX through DHFR gene amplification. To determine whether a similar situation existed in our L1210/DDP cells we investigated DHFR gene amplification, expression, protein levels, enzyme activity and inhibition of enzyme activity by MTX (24). None of these parameters were altered in L1210/DDP cells as compared to L1210 cells. It is thus clear that MTX resistance seen in the L1210/DDP cells is not due to changes in DHFR.

Folylpolyglutamate synthetase (FPGS) 
mediates formation of polyglutamates of MTX and other biologically important folates $(26,27)$. This polyglutamation enhances their cellular retention. Further, it has been shown that impaired polyglutamation alone can cause resistance to MTX (26). In order to adequately test this possibility, we measured FPGS activity in both cell lines (24). FPGS activity in L1210/DDP cells is not significantly different than in sensitive cells.

Given that other potential mechanisms of resistance, such as altered drug uptake and efflux, can also contribute to resistance, we compared drug transport in the two cell lines. If less MTX enters the cell, DHFR inhibition decreases and therefore less MTX cytotoxicity is observed. L1210/0 and L1210/DDP cells were incubated with tritiated MTX and at selected times aliquots were removed to measure the amount of cell-associated drug. A two-fold difference between the two cell lines was seen. While this represents a significant difference, it cannot by itself explain the remarkable resistance expressed by L1210/DDP cells. Additionally, we tested whether MTX efflux was greater in L1210/ DDP cells than in L1210/0 cells. Our results show MTX efflux to be similar in the two cell lines. All of the above results are summarized in Figure 1.

\section{Methotrexate transport in L1210 and L1210/DD P cells}

The studies described above can only ascertain differences in MTX association but not actual MTX uptake and intracellular distribution. Hence, it is possible that L1210/ DDP cells have a vastly different intracellular MTX concentration compared to L1210/ 0 cells.

To address this possibility, we used an $\left[{ }^{125} \mathrm{I}\right]$-labeled photoaffinity probe for MTX. L1210/0 and L1210/DDP cells were incubated with the photo probe for $5 \mathrm{~min}$ at $4{ }^{\circ} \mathrm{C}$, washed and resuspended in prewarmed buffer. Aliquots were removed at selected time intervals and exposed to UV light to covalently link the photo probe to its associated protein. The cells were then washed, lysed and the cell lysates were subjected to SDS-PAGE. Protein bands linked to the MTX photoaffinity probe, including $66,48,38$, and $21 \mathrm{kDa}$, were identified by autoradiography (Figure 2). In contrast, the MTX analog was only associated with a $68-\mathrm{kDa}$ protein in L1210/DDP cells with no transfer to additional folate transport proteins.

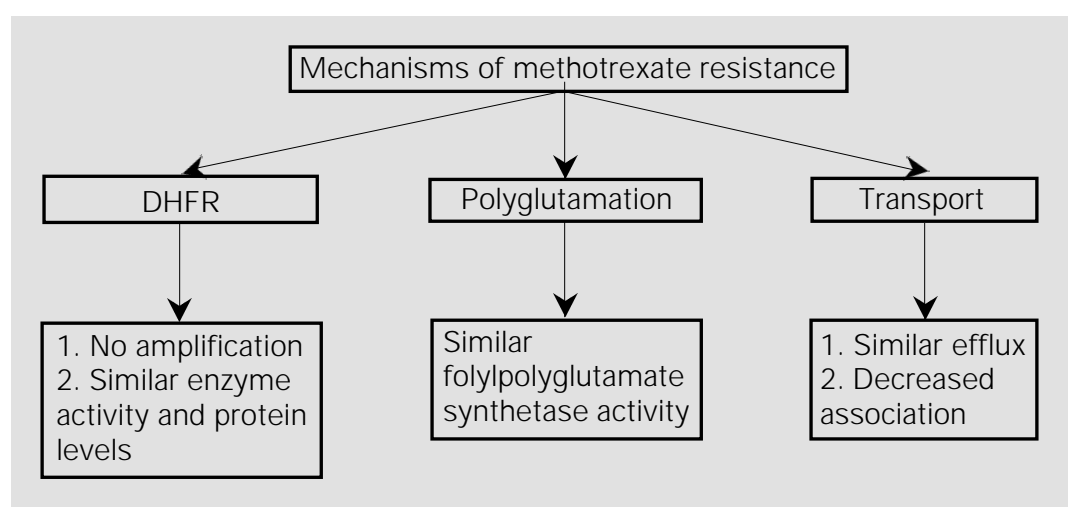

Figure 1 - Summary of mechanisms of methotrexate resistance in cisplatin-selected L1210/ 0 cells. DHFR, Dihydrofolate reductase.

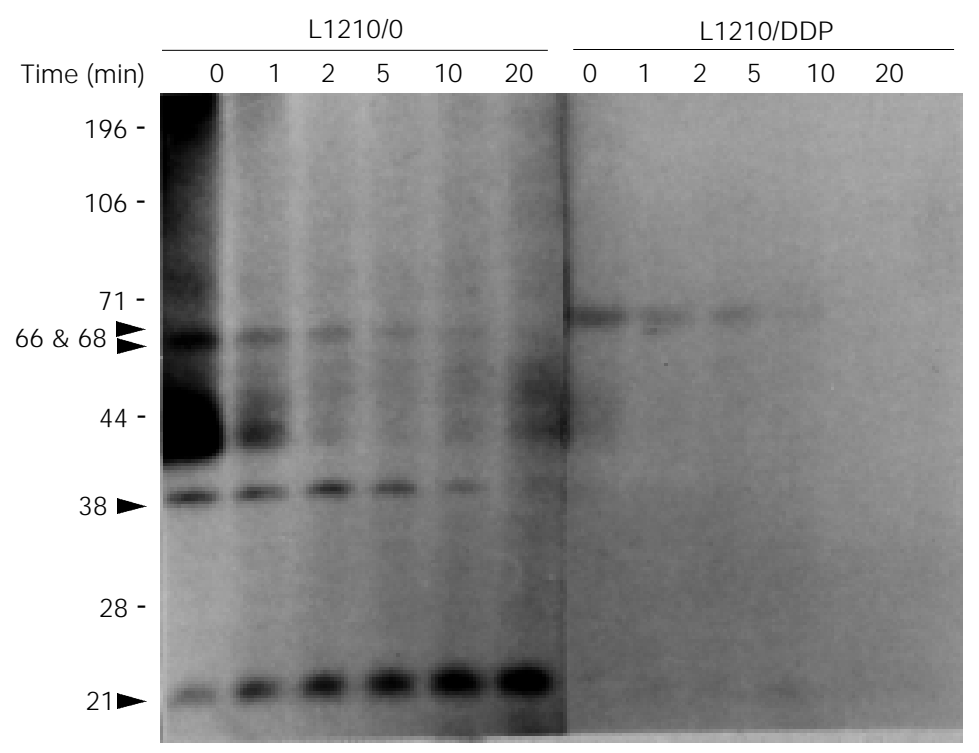

Figure 2 - Photoaffinity labeling of L1210/0 and L1210/DDP cells. Equal numbers of cells were treated with a photoaffinity analog of methotrexate, exposed to UV after various time intervals. Cells were washed, and lysates were analyzed by SDS-PAGE and autoradiographed. (Reprinted from Ref. 25, with permission from Elsevier Science). 
Figure 3 - Western blot analysis of cell lysates, membranes and cytosolic fractions from L1210/0 and L1210/DDP cells using an antibody to phosphotyrosine. (Reprinted from Ref. 25, with permission from Elsevier Science).
It is important to realize that while most drugs enter cells through passive diffusion, methotrexate utilizes the reduced folate uptake system. If the uptake system is inoperative in L1210/DDP cells, as we hypothesize, then $\left[{ }^{3} \mathrm{H}\right]$-MTX will not measure true drug uptake. Instead, it demonstrates association with membrane-bound proteins. Changes in MTX transport are measured by the covalent binding of the photoaffinity analog (Figure $2) .\left[{ }^{3} \mathrm{H}\right]-$ MTX shows only the association with the cells.

The temporal relationship in MTX transfer seen in the L1210/0 cells supports an orderly transfer of MTX from 66- to 48- to $38-$ to $21-\mathrm{kDa}$ proteins. These results provide valuable information with respect to possible components of MTX resistance. No affinity label was associated with any of the putative folate transport proteins in the L1210/DDP cells, indicating that MTX is not delivered to DHFR. This strengthens the argument that the mechanism of resistance

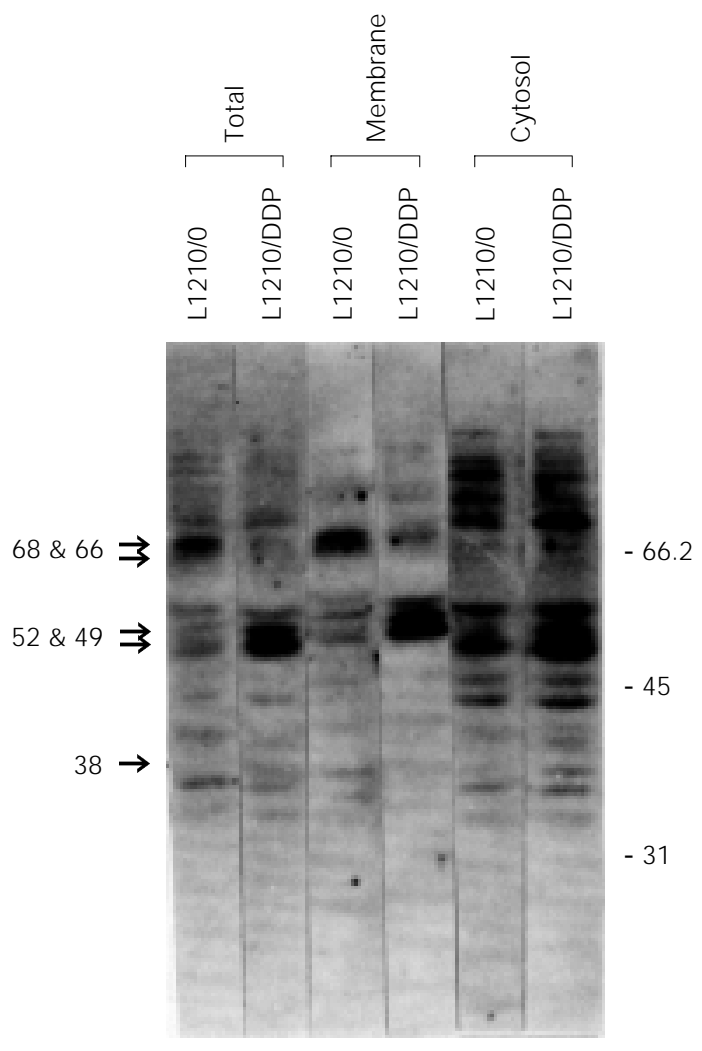

in L1210/DDP cells rests in blockade of MTX transport and not in altered DHFR. That the MTX analog was not transported beyond the 68 -kDa membrane protein implicates the 68 - and $48-\mathrm{kDa}$ proteins in faulty MTX transport. While MTX association does occur in the L1210/DDP cells, transport stops at the membrane. This could account for the rather small differences in MTX association (2-fold) but large differences in drug sensitivity (25,000-fold) between L1210/0 and L1210/DDP cells.

Binding studies done by other investigators (17) using L1210 cells showed the 66$\mathrm{kDa}$ band, but they suggested it to be unwashed bovine serum albumin (BSA). We have addressed this concern by Western blot and amino acid analyses (25).

\section{Mechanism of impaired transport}

The results discussed above implicate a faulty protein shuttle system in the type of MTX resistance expressed by the L1210/ DDP cells. Why MTX is not transported in the L1210/DDP cells was the focus of the next series of experiments.

Protein phosphorylation is required for activation of a number of functional proteins related to growth regulation and signal transduction. To date, however, tyrosine phosphorylation has not generally been associated with membrane transport proteins. Our work indicates that the tyrosine phosphorylation of the folate-binding proteins may be involved in the altered transport of MTX into the cell. Figure 3 shows a Western blot of total, membrane and cytosolic proteins of L1210/0 and L1210/DDP cells probed with an antibody to phosphotyrosine. Differences are seen in cytosolic proteins with molecular weight 74 - and $38-\mathrm{kDa}$, and also membranebound $68-, 66-\mathrm{kDa}$ proteins and proteins in the range of $48-52 \mathrm{kDa}$. Of specific interest are the membrane proteins, especially the 66- and 68-kDa proteins, since we have demonstrated, using the photoaffinity analog of 
MTX (17), that the transfer of the MTX analog to DHFR is blocked at this stage in L1210/DDP cells. Altered tyrosine phosphorylation at the $68-\mathrm{kDa}$ protein in the resistant cells may explain the decrease in photoaffinity analog binding in resistant cells at $0^{\circ} \mathrm{C}$. The increase in phosphorylation of the 48$\mathrm{kDa}$ protein in the L1210/DDP cells as compared to L1210/0 cells may block MTX binding or MTX transfer from the 68 -kDa protein to the $48-\mathrm{kDa}$ protein.

To further confirm that the tyrosine phosphorylated $66-68-\mathrm{kDa}$ band was a methotrexate-binding protein, the cells were labeled with the $\left[{ }^{125} \mathrm{I}\right]$-labeled photoaffinity analog in the presence and absence of methotrexate. Cell lysates were prepared and immunoprecipitated with an antiphosphotyrosine antibody. The 66-68-kDa band was found to be labeled and MTX competed with the labeling. That the labeling competed with methotrexate shows that the methotrexatebinding protein as seen by the photoaffinity labeling (25) is tyrosine phosphorylated and that the photoaffinity analog competitively binds the methotrexate-binding proteins.

To determine if the cellular membrane (with protein $66-68 \mathrm{kDa}$ ) was the barrier to methotrexate transport, the sensitive and resistant cells were disrupted by sonication, treated with the methotrexate photoaffinity analog, and exposed to UV light. The proteins were separated by SDS-PAGE, the gel dried and autoradiographed (Figure 4). The methotrexate analog was bound to dihydrofolate reductase $(21 \mathrm{kDa})$ in both cell lines equally, showing that it is a defect in the membrane transport proteins that results in impaired transport to DHFR. A strong band at the bottom is the free unbound $\left[{ }^{125} \mathrm{I}\right]$ labeled photoaffinity analog.

Although we have shown by different studies that impaired MTX uptake is responsible for this resistance, the sonication experiment substantiates the importance of the membrane in MTX sensitivity. For DHFR to be inhibited by MTX, it has to bind the drug.

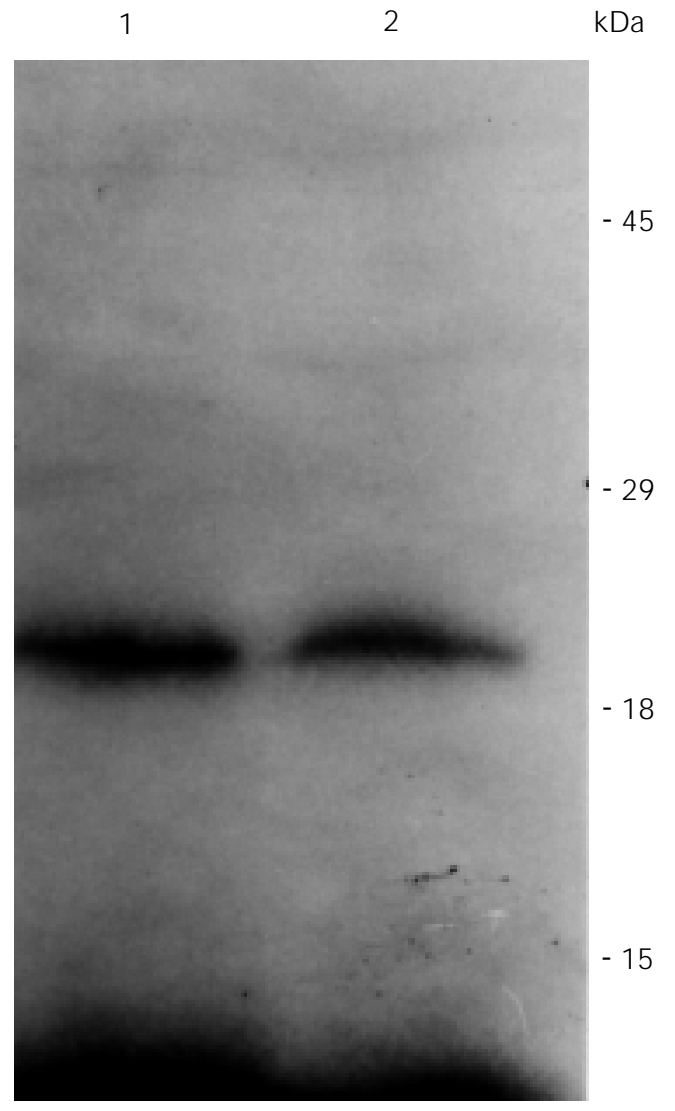

These studies emphasize that it can do so equally in the sonicated cell lysates of both cell lines. The high resistance in L1210/DDP cells can only be explained due to reduced uptake of MTX. Without a functional transport protein, the membrane barrier stops MTX from entering the cell and results in high drug resistance. Once the membrane barrier is eliminated, MTX goes to its target enzyme. The issue is the lack of transport, as shown in photoaffinity experiments using intact L1210/DDP cells (Figure 2).

\section{Modulation of tyrosine phosphorylation results in methotrexate sensitivity}

To determine if the transport of MTX requires tyrosine phosphorylation, we used the tyrosine kinase-inhibiting drug, genistein. We studied three effects of genistein treatment (28) on L1210/0 cells: 1) MTX sensi-
Figure 4 - L1210/0 and L1210/ DDP cells were sonicated and the suspension incubated with [125I]-labeled photoaffinity analog. The mixture was exposed to UV light and proteins separated by SDS-PAGE and autoradiographed. 


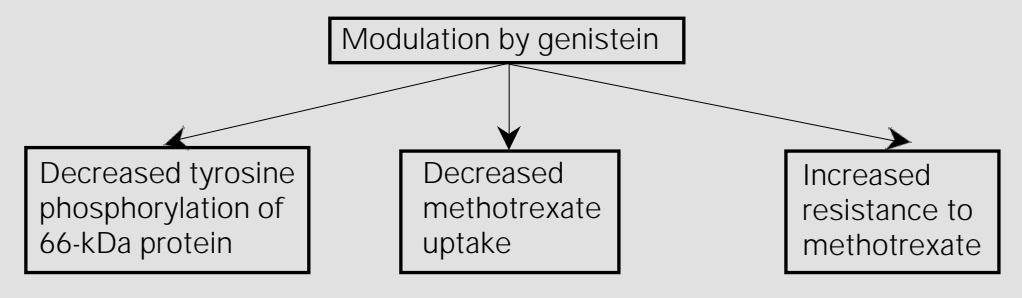

Figure 5 - Summary of results obtained after treatment of L1210/0 cells with genistein (28).

tivity, 2) MTX association and 3) tyrosine phosphorylation. Genistein pretreatment partially protected the L1210/0 cells from MTX cytotoxicity and decreased both MTX association and $68-\mathrm{kDa}$ protein tyrosine phosphorylation (Figure 5). This information provides further links for tyrosine phosphorylation with MTX transport.

\section{Conclusion}

This observation of different tyrosine phosphorylation patterns was somewhat surprising. While tyrosine phosphorylation has been commonly associated with cell growth and differentiation (29-31), we now propose a role in membrane transport. Approximately one-third of all oncogenes encode tyrosine kinases which transfer the terminal phosphate of ATP to the hydroxyl group of tyrosine residues in a protein. In addition, many growth factor receptors function as tyrosine kinases. These proteins, as well as class I oncogenes, are located on the plasma membrane.

In normal cells the growth factor receptors function as tyrosine kinases only after the growth factor binds to its receptor. Specific protein targets within the cell are then phosphorylated as part of the signal trans- duction pathway. As a result, the cell undergoes growth and division. This signal input lasts for only a prescribed period of time after which the signal is lost. Tyrosine kinase activity is then down-regulated and cell growth and division cease.

In malignant cells a different scenario exists. In many situations, tyrosine kinases are coded for by activated oncogenes and phosphorylate their substrates in a constitutive manner. In such cells the oncogene expression is deregulated, hence tyrosine phosphorylation continues and growth signals remain unabated. Inhibition of tyrosine kinase by such compounds as genistein results in growth arrest and differentiation (32).

Although the preponderance of data accumulated to date relates to the role of tyrosine kinases in cell growth and differentiation, proteins known to be crucially involved in cell-substratum adhesion have also been identified as substrates for this enzyme system. Our studies provide yet another potential role for tyrosine phosphorylation.

In summary, as we pursued the observation that L12010/DDP cells demonstrate collateral resistance to MTX, it became increasingly more relevant to observe that the resistance appears not to be related to well-characterized mechanisms of resistance such as increased DHFR and polyglutamation. The mechanism seems to involve control of drug transport across the cell membrane by a $66-$ $\mathrm{kDa}$ protein.

\section{Acknowledgments}

We thank Ms. Samantha Armstrong for careful help with the manuscript. 


\section{References}

1. Hakes $T$, Markman M, Reichman B, Hoskins W, J ones W \& Lewis J (1989). Pilot trial of high intensity intravenous cytoxan/cisplatin and intraperitoneal cisplatin for advanced ovarian cancer. Proceedings of the American Society of Clinical Oncology, 8: 152 (Abstract).

2. Ozols RF \& Young RC (1984). Chemotherapy of ovarian cancer. Seminars in Oncology, 11: 251-263.

3. Ozols RF (1989). Cisplatin dose intensity. Seminars in Oncology, 16: 22-30.

4. Fujii $R$, Mutoh $M$, Niwa $K$, Yamada $K$, Aikou T, Nakagawa $M$, Kuwano $M$ \& Akiyama S (1994). Active efflux system for cisplatin in cisplatin-resistant human KB cells. J apanese J ournal of Cancer Research, 85: 426-433.

5. Bier H (1993). Chemotherapeutic drug resistance in the management of head and neck cancer. European Archives of OtoRhino-Laryngology, 250: 200-208.

6. Osmak M, Beketic-Reskovic L, Matulic M \& Soric J (1993). Resistance of human larynx carcinoma cells to cisplatin, gamma irradiation and methotrexate does not involve over expression of c-myc or c-Ki-ras oncogenes. Mutation Research, 303: 113120.

7. Hill BT, Shellard SA, Hosking LK, Dempke WC, Fichtinger-Schepman AM, Tone T, Scanlon KJ \& Whelan RD (1992). Characterization of cisplatin-resistant human ovarian carcinoma cell line expressing cross-resistance to 5-FU but collateral sensitivity to methotrexate. Cancer Research, 52: 3110-3118.

8. Schabel J r FM, Skipper HE, Trader MW, Laster WR, Griswold DP \& Corbett TH (1983). Establishment of cross resistance profiles for new agents. Cancer Treatment Reports, 67: 905-922.

9. Teicher BA, Cucchi CA, Lee JB, Flatow J L, Rosowsky A \& Frei 3rd E (1986). Alkylating agents: in vitro studies of cross resistance patterns in human cell lines. Cancer Research, 46: 4379-4383.

10. Scanlon KJ , Newman EM, Lu Y \& Priest DG (1986). Biochemical basis for cisplatin and 5-fluorouracil synergism in human ovarian carcinoma cells. Proceedings of the National Academy of Sciences, USA, 83: 8923-8925.

11. Rosenberg B (1979). Anticancer activity of cisplatin and some relevant chemistry. Cancer Treatment Reports, 63: 14331438.

12. Erickson LC, Zwelling LA, Durcoe JM,
Sharkey NA \& Kohn KW (1981). Differential cytotoxicity and DNA cross-linking in normal and transformed human fibroblasts treated with cis-diamminedichloroplatinum (II). Cancer Research, 41: 27912794.

13. Roberts J J, Knox RJ , Perna MF, Friedlos F \& Lydall DA (1988). The role of platinum drug-DNA interactions in cellular toxicity and anti-tumor effects. In: Nicolini M (Editor), Platinum and Other Metal Coordination Compounds in Cancer Chemotherapy. Martinus-Nijhoff Publishing, Boston, 69-70.

14. Futterman S \& Silverman M (1957). The inactivation of folic acid by liver. J ournal of Biological Chemistry, 224: 31-43.

15. Taylor IW \& Tattersall MH (1981). Methotrexate cytotoxicity in cultured human leukemic cells studied by flow cytometry. Cancer Research, 41: 1549-1558.

16. Price $E M$, Ratnam $M$, Rodeman $K M$ \& Freisheim J H (1988). Characterization of the methotrexate transport pathway in murine L1210 leukemia cells: involvement of a membrane receptor and cytosolic protein. Biochemistry, 27: 78537858.

17. Price EM \& Freisheim J H (1987). Photoaffinity analogues of methotrexate as folate antagonist binding probes. 2. Transport studies, photoaffinity labeling and identification of the membrane carrier protein for methotrexate from murine L1210 cells. Biochemistry, 26: 4757-4763.

18. Sirotnak FM, Moccio DM, Kelleher LE \& Guotas LJ (1981). Relative frequency and kinetic properties of the transport defective phenotypes among methotrexate resistant L1210 clonal cell lines derived in vivo. Cancer Research, 41: 4447-4452.

19. Rosowsky A, Wright JE, Cucchi CA, Lippke J A, Tantravahi R, Envin TJ \& Frei 3rd E (1985). Phenotypic heterogeneity in cultured human head and neck squamous cell carcinoma lines with low level methotrexate resistance. Cancer Research, 45: 6205-6212.

20. Dembo $M \&$ Sirotnak FM (1984). Membrane transport of folate compounds. In: Folate Antagonists as Therapeutic Agents. 1: 173-217.

21. McCormick J I, Susten SS \& Freisheim J H (1981). Characterization of the methotrexate transport defect in a resistant L1210 lymphoma cell line. Archives of Biochemistry and Biophysics, 212: 311-318.

22. J ansen G, Westerhof R, Kathmann I,
Rademaker BC, Rijksen G \& Schornagel J H (1989). Identification of a membrane associated folate binding protein in human leukemic CCRF-CEM cells with transport related methotrexate. Cancer Research, 49: 2455-2459.

23. Freisheim JH, Price EM \& Ratnam $M$ (1989). Folate coenzyme and antifolate transport proteins in normal and neoplastic cells. Advances in Enzyme Regulation, 29: 13-26.

24. Wroblewski DH, Bhushan A, Xuan Y, Tritton TR \& Hacker MP (1996). Investigations on the mechanisms of methotrexate resistance in a cisplatin resistant L1210 urine leukemia cell subline. Cancer Chemotherapy and Pharmacology, 37: 337-342.

25. Bhushan A, Wroblewski DH, Tritton TR, Xuan Y \& Hacker MP (1996). Altered tyrosine phosphorylation in cisplatin resistance. Biochemical Pharmacology, 51: 477-482.

26. McGuire JJ \& Bertino J R (1981). Enzymatic synthesis and function of folypolyglutamates. Molecular and Cellular Biochemistry, 38: 19-48.

27. McClosky DE, McGuire JJ, Russell CA, Rowan BG, Bertino J R, Pizzomo G \& Mini E (1991). Decreased folypolyglutamate synthetase activity as a mechanism of methotrexate resistance in CCRF-CEM human leukemia sublines. J ournal of Biological Chemistry, 266: 6181-6187.

28. Xuan Y, Hacker MP, Tritton TR \& Bhushan A (1998). Modulation of methotrexate resistance by genistein in murine leukemia L1210 cells. Oncology Reports, 5: 419421.

29. BishopJ M (1983). Cellular oncogenes and retroviruses. Annual Review of Biochemistry, 52: 301-354.

30. Hanks SK, Quinn AM \& Hunter T (1988). The protein kinase family: conserved features and deduced phylogeny of the catalytic domains. Science, 241: 42-52.

31. Glenney J r J G, Zokas L \& Kamps MP (1988). Monoclonal antibodies to phosphotyrosine. J ournal of Immunological Methods, 109: 277-285.

32. Akiyama T, Ishida J, Nakagawa S, Ogawara H, Watanabe S, Itoh N, Shibuya M \& Fukami Y (1987). Genistein, a specific inhibitor of tyrosine protein kinases. J ournal of Biological Chemistry, 262: 5592-5595. 